\title{
Gastrointestinal motility disorders in neurologic disease
}

\author{
Michael Camilleri \\ Clinical Enteric Neuroscience Translational and Epidemiological Research (CENTER), Division of Castroenterology and Hepatology, Mayo Clinic, Rochester, Minnesota, USA
}

\begin{abstract}
The extrinsic and autonomic nervous system intricately controls the major functions of the gastrointestinal tract through the enteric nervous system; these include motor, secretory, sensory, storage, and excretory functions. Disorders of the nervous system affecting gastrointestinal tract function manifest primarily as abnormalities in motor (rather than secretory) functions. Common gastrointestinal symptoms in neurologic disorders include sialorrhea, dysphagia, gastroparesis, intestinal pseudo-obstruction, constipation, diarrhea, and fecal incontinence. Diseases of the entire neural axis ranging from the cerebral hemispheres to the peripheral autonomic nerves can result in gastrointestinal motility disorders. The most common neurologic diseases affecting gastrointestinal function are stroke, parkinsonism, multiple sclerosis, and diabetic neuropathy. Diagnosis involves identification of the neurologic disease and its distribution, and documentation of segmental gut dysfunction, typically using noninvasive imaging, transit measurements, or intraluminal measurements of pressure activity and coordination of motility. Apart from treatment of the underlying neurologic disease, management focuses on restoration of normal hydration and nutrition and pharmacologic treatment of the gut neuromuscular disorder.
\end{abstract}

\section{Introduction}

The scope of this Review is to familiarize neurologists, neurosurgeons, and gastroenterologists with the gastrointestinal neuromuscular apparatus and its extrinsic and intrinsic neural control, as well as gastrointestinal symptoms and manifestations that are well documented in neurologic diseases.

\section{The gastrointestinal neuromuscular apparatus}

Gastrointestinal motor, transport, secretory, storage, and excretory functions result from intricately balanced control mechanisms (Figure 1). Motility results from changes in the electrical and contractile properties of smooth muscle cells that result from transmembrane fluxes of ions controlled by chemical neurotransmitters (e.g., acetylcholine, biogenic amines, neuropeptides, and nitric oxide) and circulating hormones (e.g., serotonin). Enteric mechanisms are regulated by extrinsic (sympathetic and parasympathetic) pathways. Disorders of the nervous system affecting gastrointestinal tract function are manifested primarily as abnormalities in motor (rather than sensory or secretory) functions.

\section{The digestive tract's extrinsic and enteric nervous systems}

In the mammalian digestive tract, the intrinsic, or enteric, nervous system (ENS) contains about 100 million neurons, approximately

Conflict of interest: MC owns equity in Enterin Inc., which is developing ENT-01 for Parkinson disease. In the past year, MC has received research grants from Allergan (eluxadoline for bile acid diarrhea), Takeda (TAK-954 for gastroparesis), and ILSI North America (intestinal permeability). MC has submitted patent applications for (a) capsule for colonic transit by scintigraphy (publication number US5827497A); (b) 13C-mannitol for permeability measurements (publication number US20190145953) and (c) obesity-metabolomics to identify different phenotypes (publication number W02019104146A1).

Copyright: () 2021, American Society for Clinical Investigation.

Reference information: J Clin Invest. 2021;131(4):e143771.

https://doi.org/10.1172/JCl143771. equivalent to the number present in the spinal cord. The ENS is an integrative system of ganglionated nerve plexuses, including the myenteric (Auerbach's) plexus located between the two muscular layers of the muscularis externa, and the submucosal (Meissner's) plexus (Figure 1). The myenteric plexus extends from the pharyngoesophageal junction to the internal anal sphincter. Each ganglion within the plexuses contains up to 100 nerve cell bodies. The submucosal plexus is sparse in the stomach, whereas, in the small and large intestines, it is composed of either large or small ganglia interlinked by internodal strands containing hundreds of axons.

Within the plexuses, the interstitial cells of Cajal, identified as cells positive for tyrosine kinase (cKit), and fibroblast-like cells (PDGFR $\alpha$-positive) constitute the electrical syncytium or pacemakers of the digestive tract, integrating neuromuscular activity controlled by the ENS. The ENS is separate from the autonomic nervous system. It has several components: sensory mechanoreceptors and chemoreceptors, interneurons that process sensory input and control motor and sensory units, and effector secretory or motor neurons. Preprogrammed neural circuits integrate motor function within and between different regions to coordinate gut functions such as the peristaltic reflex (Figure 2) and the interdigestive migrating motor complex or induce epithelial cell secretion of fluids and electrolytes. By controlling the programmed circuits in the gut, relatively few vagal preganglionic and sympathetic postganglionic fibers are able to control 100 million enteric plexus neurons (Figure 1).

The synaptic pathways in the gut wall respond to sensory input (e.g., of luminal content) and to modulation via vagal and sacral spinal nerves (S2-4), preganglionic parasympathetic fibers (which are generally excitatory), and sympathetic postganglionic nerves (which originate from the fifth thoracic to second lumbar section of the spinal cord), and are generally inhibitory to muscle layers by allowing activity of intrinsic inhibitory innervation by enteric nerves (e.g., vasoactive intestinal peptidergic [VIPergic], nitrergic [NOergic]). Sympathetic nerves also stimulate sphincters. Extrin- 

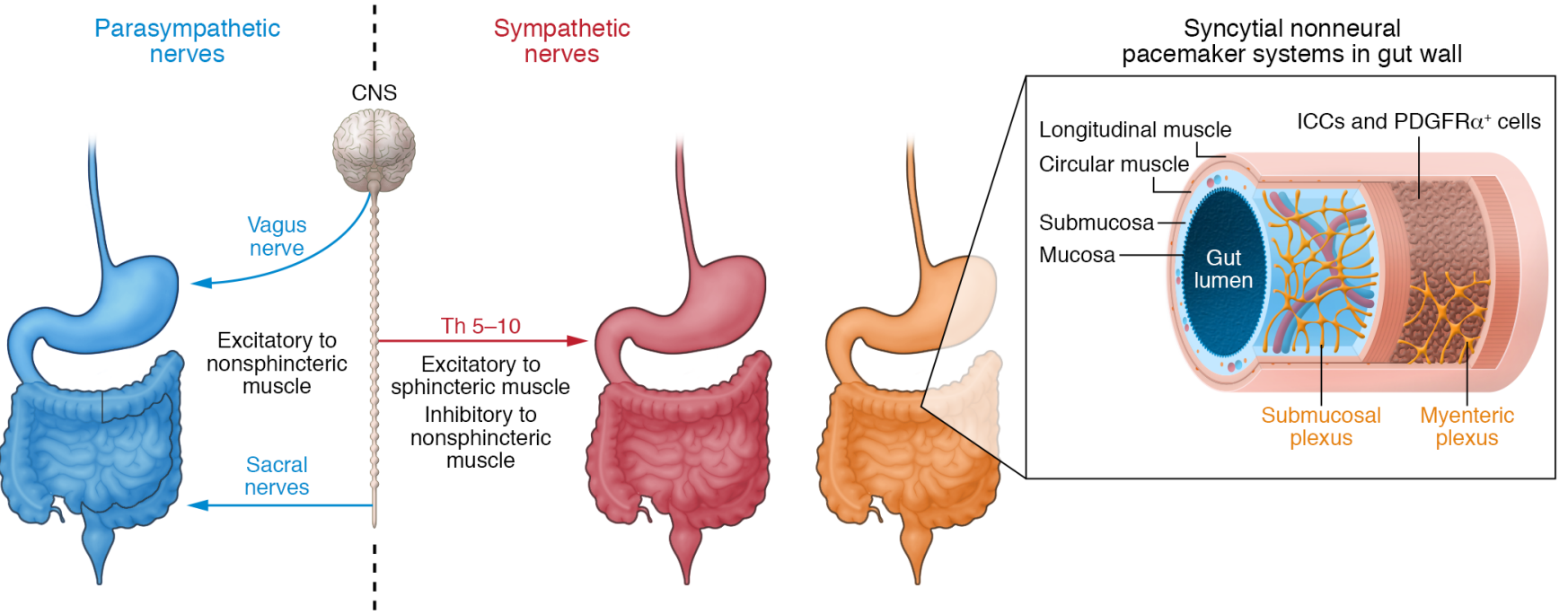

Figure 1. Control of gut motility: extrinsic autonomic neural control, enteric nervous system, and smooth muscle function. The left panel shows extrinsic neural control, including the vagus and sacral parasympathetic nerves (blue) and the sympathetic innervation (red) originating from levels thoracic 5 to lumbar 2 in the spinal cord. The right panel shows the organization of the enteric nervous system, which demonstrates plexuses in the submucosal and intermuscular layers called the submucosal plexus and myenteric plexus. In addition, there are pacemakers in the wall of the intestine, including the interstitial cells of Cajal (ICCs) and fibroblast-like cells bearing receptors for PDCFR $\alpha$, which convey the neural stimulus to the smooth muscle cells. These pacemaker cells and plexuses help to coordinate muscular and secretory functions of the digestive tract.

sic vagal fibers also synapse with non-adrenergic inhibitory intramural neurons in the gut (e.g., NOergic, enkephalinergic, and VIPergic; and sympathetic noradrenergic fibers) to induce gastric accommodation. Loss of the sympathetic inhibitory control ("the brake") may manifest with gut motor activity, including diarrhea.

Sensory mechanisms mediated by motor neurons, chemoreceptors, and intrinsic primary afferent neurons and pathways originating in the gastrointestinal tract activate intrinsic, local, and regional reflexes that control motor, secretomotor, and vasomotor responses. Visceral afferents, which course along sympathetic nerves or within the vagus nerve, convey gut sensations to prevertebral ganglia or the nodose ganglia, respectively, and enter the CNS through the dorsal horn of the spinal cord or the nucleus tractus solitarius of the vagal complex. Stimuli ascend to higher centers and result in conscious perception of gut stimuli such as pain.

Prevertebral (celiac, superior mesenteric, and inferior mesenteric) ganglia function as relay stations between the CNS and periphery $(1,2)$. The prevertebral ganglia are also connected with one another. The principal ganglion cells receive input from the preganglionic sympathetic nerves arising in the dorsolateral column of the spinal cord. The ganglia integrate neural supply from central and peripheral sources and participate in peripheral reflex activity (1). There are two main types of reflexes: spinal reflexes involving visceral afferent (e.g., splanchnic and lumbar colonic) nerves, dorsal root ganglia, and preganglionic autonomic neurons; and peripheral reflexes (3) involving afferent peptidergic fiber projections to the prevertebral ganglia and efferent projections of noradrenergic neurons. The latter reflexes mediate the crosstalk that occurs between different regions (1), and they mediate peristalsis, and responses to intestinal distention (enteroenteric reflexes).
Table 1 summarizes wiring and functions of the extrinsic neural pathway to the digestive tract (4).

\section{Muscular components involved in gastrointestinal motility}

The specialized, circumferential muscularis mucosae located between the lamina propria and the submucosa functions to allow surface absorptive cells to get into close contact with the intraluminal content. The muscularis propria (or externa) is composed of an inner, thicker circular layer and an outer, thinner longitudinal layer. The longitudinal layer covers the entire circumference in the esophagus, small intestine, and rectum. In the colon, it is separated into three taeniae coli. In addition, the stomach has a third oblique smooth muscle layer. The spindle-shaped smooth muscle cells are 40-100 $\mu \mathrm{m}$ long and 2-8 $\mu \mathrm{m}$ in diameter and are tightly packed, with little connective tissue and with special contacts to allow for electrical coupling with the electrical syncytium. The gap junctions between the smooth muscle cells are essential for the sheets of muscle to be controlled by a few cells at the nerve-muscle interface.

\section{Common gastrointestinal symptoms and syndromes in neurologic disorders}

Table 2 outlines common gastrointestinal symptoms and syndromes in neurologic disorders as well as investigation and principles of management: dysphagia, gastroparesis $(5,6)$, chronic intestinal pseudo-obstruction (6-10), constipation (11-14), and fecal incontinence $(11,14)$. The symptoms are often associated with peripheral sensory or motor dysfunctions, as well as autonomic symptoms such as postural dizziness, visual disturbance in the presence of bright lights, and abnormalities of sweating. 


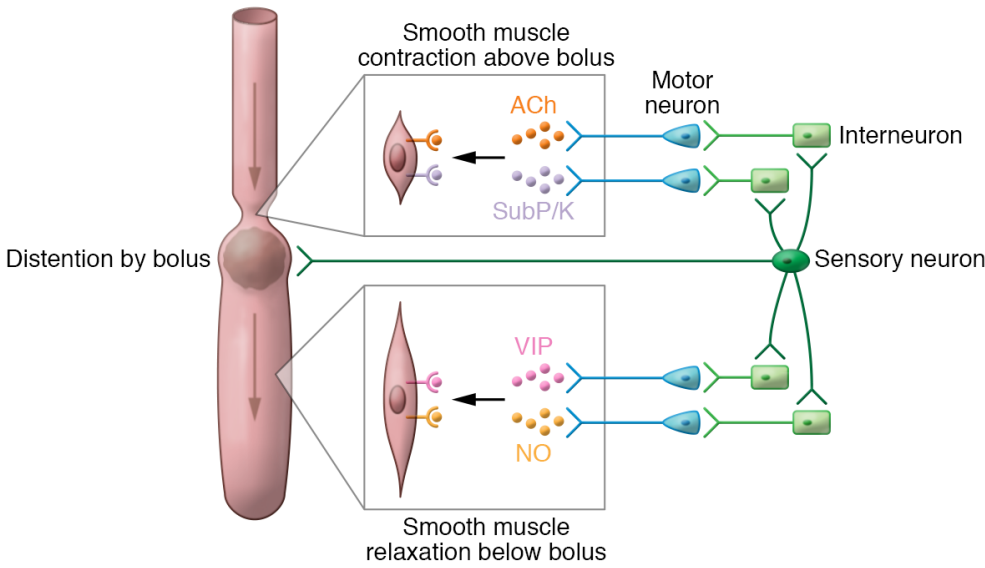

Figure 2. Components of the peristaltic reflex and relationship to enteric and extrinsic neural control. In the peristaltic reflex, distension of the intestine by a bolus is sensed by the intrinsic primary afferent neurons, which stimulate interneurons to activate ascending contraction proximal to the bolus through excitatory neurons. Stimulation of muscles occurs through effects of transmitters such as acetyl choline and neurokinins such as substance $P$ and substance $K$. The intrinsic primary afferent neuron also stimulates descending inhibition in the receiving segment of the intestine distal to the bolus, and this effect is mediated by inhibitory transmitters, such as VIP and nitric oxide (NO). rather than carotid territories) and may cause malnutrition or aspiration pneumonia $(15,16)$. Videofluoroscopy of the pharynx and upper esophagus typically shows transfer dysphagia or tracheal aspiration. Colonic pseudo-obstruction occurs rarely. The severity of the initial neurologic deficit is the strongest predictor of eventual recovery.

Percutaneous endoscopic gastrostomy (PEG) may be required to provide nutrition and facilitate rehabilitation in the first weeks after a stroke. Swallowing typically improves in a majority of stroke survivors over 1-12 weeks, after which oral intake resumes and the gastrostomy tube can be removed. Compared with nasogastric tube feeding, PEG reduces treatment failures and gastrointestinal bleeding, and has higher feed delivery and serum albumin concentration. Nutritional supplementation is associated with reduced pressure sores and increased energy and protein intake (17).

Systematic reviews on behavioral interventions and acupuncture or electrical stimulation for dysphagia in patients with stroke provide contradictory conclusions on efficacy $(17,18)$.

The second prominent gastrointestinal symptom

\section{Extrinsic neurologic disorders causing gut dysmotility}

This Review focuses on diseases of extrinsic neural control (brain diseases, autonomic system degenerations, spinal cord lesions, peripheral neuropathy) and muscle diseases affecting gut motility. The bidirectional relationship of the brain and gut is consolidated by evidence that the gut is a portal of entry for substances such as prions in neurologic diseases such as Alzheimer disease, Parkinson disease, and transmissible spongiform encephalopathies (Figure 3).

\section{Brain diseases}

Stroke. Dysphagia in stroke may result from cranial nerve involvement (more likely in the context of strokes in the vertebrobasilar in stroke patients is constipation, which affects about $45 \%$ in the acute stage and $48 \%$ in the rehabilitation stage (19). Patients with brainstem stroke had increased prevalence of constipation and decreased rectal sensation (20) compared with stroke in patients without brainstem lesions. Among stroke patients with constipation, approximately $30 \%$ had overall colonic transit delay (>60 hours), particularly in proximal rather than rectosigmoid colon (21).

Head injury. Immediately following moderate to severe head injury, there are transient delays in gastric emptying that are correlated with the severity of the injury and increased intracranial pressure. The underlying mechanism is unknown. Patients may require parenteral nutrition temporarily before resuming enteral nutrition within a few weeks.
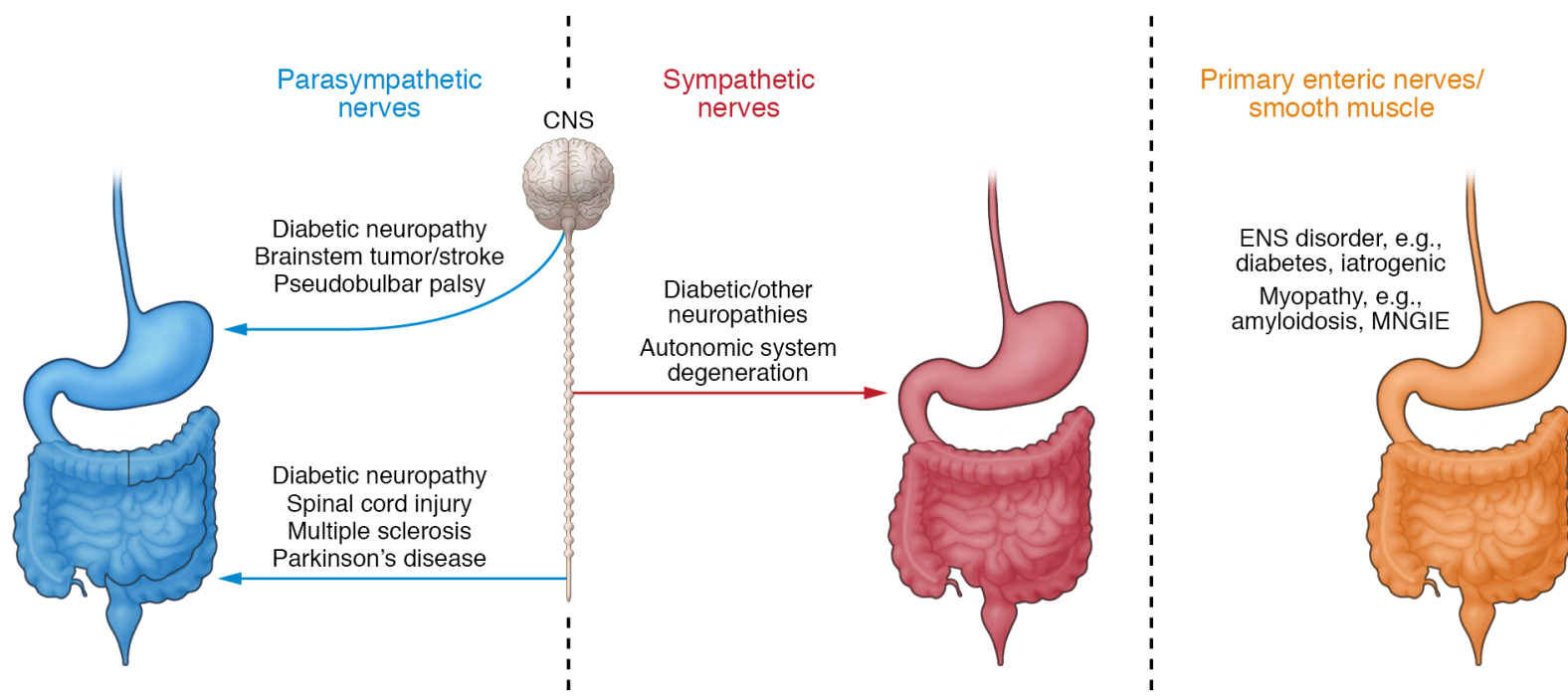

Figure 3. Neurologic disorders known to affect gastrointestinal motility. These disease processes involve craniosacral parasympathetic pathways (left), sympathetic pathways (middle), and/or primary enteric nerves or smooth muscle (right). ENS, enteric nervous system. 
Table 1. Wiring and functions of extrinsic neural control

\begin{tabular}{|c|c|c|c|c|c|}
\hline \multirow[b]{2}{*}{ Region } & \multicolumn{2}{|c|}{ Parasympathetic } & \multicolumn{2}{|c|}{ Sympathetic } & \multirow[t]{2}{*}{ Central mechanism } \\
\hline & Wiring & Function & Wiring & Function & \\
\hline \multicolumn{6}{|l|}{ Esophagus } \\
\hline Cervical esophagus & $\begin{array}{l}\text { Clossopharyngeal } \\
\text { and vagus nerve }\end{array}$ & Sensation & & & Sensory: NTS \\
\hline Thoracic esophagus & Vagus nodose ganglia & Sensation & & & Sensory: NTS \\
\hline
\end{tabular}

\section{Stomach}

\begin{tabular}{|c|c|c|c|c|c|}
\hline Contraction & Vagus nerve & $\begin{array}{l}\text { Peristalsis (cholinergic); } \\
\text { inhibitory (nonadrenergic) } \\
\text { for relaxation }\end{array}$ & $\begin{array}{l}\text { Celiac ganglion; } \\
\text { T6-9 spinal cord }\end{array}$ & $\begin{array}{l}\text { Inhibition and relaxation } \\
\text { (e.g., antrofundal reflex) }\end{array}$ & $\begin{array}{l}\text { Motor: DMV, nucleus ambiguus; } \\
\text { sensory: NTS, thoracic spinal cord }\end{array}$ \\
\hline Accommodation & Vagus nerve & $\begin{array}{l}\text { Stretch and chemosensation } \\
\text { (nonadrenergic, VIP, NO) }\end{array}$ & Spinal root ganglia; T7-11 & $\begin{array}{c}\text { Mechanosensation } \\
\text { (e.g., distention reflexes) }\end{array}$ & $\begin{array}{l}\text { Motor: DMV, nucleus ambiguus; } \\
\text { sensory: NTS, thoracic spinal cord }\end{array}$ \\
\hline \multicolumn{6}{|c|}{ Small and large intestines } \\
\hline \multirow[t]{2}{*}{$\begin{array}{l}\text { Small and large } \\
\text { intestines }\end{array}$} & Vagus nerve & $\begin{array}{l}\text { Small bowel and proximal } \\
\text { colon peristalsis and } \\
\text { sensation }\end{array}$ & $\begin{array}{l}\text { Celiac ganglion (duodenum); } \\
\text { superior MG (splanchnic nerves } \\
\text { to small bowel); T5-10 spinal cord }\end{array}$ & $\begin{array}{l}\text { Motor inhibition; } \\
\text { distention reflexes }\end{array}$ & $\begin{array}{l}\text { Sensory: NTS; sensory and motor: } \\
\text { DMV and thoracic spinal cord; motor: } \\
\text { parasympathetic spinal nucleus }\end{array}$ \\
\hline & Sacral S2-4 & $\begin{array}{l}\text { Distal colon peristalsis } \\
\text { and sensation }\end{array}$ & $\begin{array}{l}\text { Inferior MG (lumbar colonic } \\
\text { nerves); T9-10 spinal cord }\end{array}$ & & $\begin{array}{l}\text { Sensory: NTS; sensory and motor: } \\
\text { DMV and thoracic spinal cord; motor: } \\
\text { parasympathetic spinal nucleus }\end{array}$ \\
\hline lleocecal sphincter & Vagus nerve & Sphincter contraction & $\begin{array}{l}\text { Splanchnic and lumbar } \\
\text { colonic nerves }\end{array}$ & $\begin{array}{l}\text { Sphincter contraction } \\
\text { ( } \alpha \text { effect })\end{array}$ & $\begin{array}{l}\text { Motor: T9-10 spinal cord; } \\
\quad \text { ? vagal nucleus }\end{array}$ \\
\hline External & S2-4 via pudendal & Voluntary control; sensation & & & $\begin{array}{l}\text { Motor and sensory: lateral part of } \\
\text { ventral horn of spinal cord }\end{array}$ \\
\hline
\end{tabular}

Adapted with permission from Lippincott-Raven Publishers (Table 1 in ref. 4). LES, lower esophageal sphincter; MC, mesenteric ganglion; NTS, nucleus tractus solitarius; RAIR, rectoanal inhibitory reflex; S, sacral; T, thoracic; UES, upper esophageal sphincter; VIP, vasoactive intestinal peptide.

Alzheimer disease and dementia. In a study of 27,076 participants with Alzheimer disease and matched controls (66\% of both groups over age 80), Alzheimer disease was associated with higher incidence of serious upper and lower gastrointestinal events (22). Treatment of dementia with acetylcholinesterase medications (e.g., donepezil or rivastigmine) was associated with gastrointestinal symptoms such as nausea, vomiting, and diarrhea $(23,24)$. These may be dose-related and may be reduced by use of transdermal preparations.

Parkinson disease. In accordance with the Braak hypothesis (25) that a pathogen reaching the gut initiates pathology that spreads to the CNS in Parkinson disease, neuropathologic studies showed accumulation of abnormal inclusions containing $\alpha$-synuclein (Lewy neurites) in the ENS, dorsal motor nucleus of the vagus (DMV), and substantia nigra (26). $\alpha$-Synuclein aggregates have been demonstrated in the submandibular gland, esophagus, and colon (submucosal and myenteric plexuses) of patients with Parkinson disease more frequently than in age-matched controls. The portals for central delivery of $\alpha$-synuclein are the olfactory bulb and vagus nerve. A Swedish population registry study showed that total truncal vagotomy, but not selective vagotomy, was associated with lower prevalence of Parkinson disease in comparison with population controls (27).

Patients with Parkinson disease experience several gastrointestinal manifestations that advance with disease duration and severity in parallel with stages of motor dysfunction (Hoehn and Yahr scale): salivary drooling (sialorrhea) resulting in speech and eating impairment and impact on quality of life of the patients and their caregivers, dysphagia, gastroparesis, constipation, defecatory dysfunction, and fecal incontinence $(28,29)$. Sialorrhea is usually secondary to impaired swallowing rather than excessive salivary production; in fact, saliva production is reduced even in early-phase Parkinson disease (30). Progression of gut symptoms was also correlated with reduction in dopamine transporter availability as shown by reduced binding of dopamine transporter to the caudate nucleus relative to the striatum (31).

Gut symptoms, particularly constipation and defecatory dysfunction, may precede the development of motor symptoms by 
Table 2. Common gastrointestinal symptoms and syndromes in neurologic disorders

\begin{tabular}{|c|c|c|c|}
\hline Gl symptom (ref.) & Neurologic mechanism & Diagnosis/evaluation & Management \\
\hline Oropharyngeal dysphagia & $\begin{array}{l}\text { Pharyngeal skeletal muscles; lower motor } \\
\text { neuron (e.g., bulbar polio or pseudobulbar } \\
\text { palsy) or muscular (e.g., ALS, myasthenia gravis) }\end{array}$ & $\begin{array}{l}\text { Physical exam: dentition, movement of the } \\
\text { uvula (IX and X cranial nerves), jaw jerk; } \\
\text { videofluoroscopy; HR manometry }\end{array}$ & $\begin{array}{l}\text { Nutritional support and prevention of } \\
\text { pulmonary aspiration }\end{array}$ \\
\hline Gastroparesis $(5,6)$ & $\begin{array}{l}\text { Vagal, myenteric denervation; iatrogenic } \\
\text { (narcotics, GLP-1 agonists) }\end{array}$ & $\begin{array}{l}\text { EGD to exclude obstruction; gastric emptying } \\
\text { (scintigraphy/GEBT); autonomic test; } \\
\text { GD manometry; pylorus test }\end{array}$ & $\begin{array}{l}\text { Support of hydration and nutrition; prokinetics } \\
\text { and antiemetics; in refractory patients, } \\
\text { ? endoscopic pyloromyotomy or PEJ feeding }\end{array}$ \\
\hline $\begin{array}{l}\text { Chronic intestinal } \\
\text { pseudo-obstruction } \\
(6-10)\end{array}$ & $\begin{array}{l}\text { Vagal, myenteric denervation; iatrogenic } \\
\text { (narcotics, GLP-1 agonists) }\end{array}$ & $\begin{array}{l}\text { Physical exam: associated neuropathy } \\
\text { elsewhere, CT enterography to exclude } \\
\text { obstruction; gastric emptying (scintigraphy/ } \\
\text { CEBT); autonomic tests; CD manometry: } \\
\text { myopathy/neuropathy }\end{array}$ & $\begin{array}{l}\text { For gastroparesis + enteral or parenteral } \\
\text { nutrition; with myopathic disease treatment } \\
\text { for small bowel bacterial overgrowth; } \\
\text { ? small bowel transplantation }\end{array}$ \\
\hline Constipation (11-14) & $\begin{array}{l}\text { Vagal, sacral parasympathetic or } \\
\text { myenteric denervation }\end{array}$ & $\begin{array}{l}\text { Physical exam: DRE; associated neuropathy } \\
\text { or spinal disease; plain x-ray (diameter, } \\
\text { stool and gas distribution); colonic transit; } \\
\text { HR ARM + balloon expulsion }\end{array}$ & $\begin{array}{l}\text { Bulk, osmotic, secretory laxatives or prokinetics; } \\
\text { pelvic floor training if sensation preserved; } \\
\text { rarely colectomy or colostomy }\end{array}$ \\
\hline
\end{tabular}

ALS, amyotrophic lateral sclerosis; DRE, digital rectal examination; ECD, esophagogastroduodenoscopy; GD, gastroduodenal; GEBT, gastric emptying breath test; GERD, gastroesophageal reflux disease; HR ARM, high-resolution anorectal manometry; PEJ, percutaneous endoscopic jejunal.

up to 20 years (32). Among treated patients, the gut symptom with the most significant progression over 18 months' follow-up was constipation (29). Typically, there is slow gastric emptying or colonic transit, although recent evidence identified a subgroup with accelerated gastric emptying (33).

Excessive salivary drooling (34) may respond to reduced production of saliva with systemic or topical anticholinergic agents, local injection of botulinum toxin, or even radiotherapy (35).

Abnormal swallowing results mainly from impaired oral (e.g., lingual), pharyngeal, and upper esophageal muscle function and is demonstrable on videofluoroscopy or esophageal manometry (36). The latter shows ineffective peristalsis or functional esophagogastric junction obstruction but not achalasia. Dysphagia is frequently associated with choking, disordered salivation, and variable degrees of malnutrition. Conservative treatment includes attention to the consistency of food (thickened liquids). With more severe dysphagia, expiratory muscle strength training (37) and video-assisted swallowing therapy (38) may be effective alone or in combination with dopaminergic therapy. Extreme dysphagia causing malnutrition or dehydration may necessitate a percutaneous gastrostomy.

Delayed gastric emptying may contribute to impaired pharmacokinetics of anti-Parkinson medications and to the on-off phenomenon (unpredictable motor symptoms during continuous treatment; ref. 39). The mainstay of treatment with levodopa, a dopamine precursor, may further inhibit gastric emptying. Two prokinetic dopamine D2 receptor antagonists are contraindicated: metoclopramide crosses the blood-brain barrier (BBB) and exacerbates motor dysfunction; domperidone does not cross the $\mathrm{BBB}$, but it is not widely available and increases risk of cardiac arrhythmia. Alternative formulations (34) by cutaneous patch, liquid, or subcutaneous delivery of an antiparkinsonian therapy, or deep brain stimulation of subthalamic nuclei, may be required. There is a paucity of treatment trials for delayed gastric emptying in Parkinson disease (40). Transcutaneous vagal nerve stimulation with an electric device reduced gastrointestinal symptom rating scale and was well tolerated in a placebo-controlled study (41).

Constipation in Parkinson disease manifests as reduced frequency or consistency, or excessive straining, and may result from generalized hypokinesia, gut hypomotility, defecatory dysfunction (typically, paradoxical contraction of the pelvic floor), and effects of anticholinergic and dopamine agonists, which retard colonic transit. In general, osmotic or secretory laxatives or prebiotic/ probiotic combinations appear to be effective. Colonic prokinetic agents have not really been subjected to well-structured and powered studies. The osmotic laxative PEG3350 (42) and the secretory agent lubiprostone (43) have been shown to be efficacious in placebo-controlled trials of constipation in Parkinson disease. In patients with defecatory dysfunction, secretory agents (liquefying consistency) or improved dopaminergic intervention (subcutaneous dopamine agonist, apomorphine; ref. 44) are required.

Preliminary evidence shows that squalamine (45), which dissolves $\alpha$-synuclein aggregates locally in the gut, relieves constipation and reduces central manifestations of Parkinson disease. If this approach with low bioavailability provides relief of symptoms beyond the gut, it would further support the Braak hypothesis.

Multiple system atrophy. Individuals with multiple system atrophy (MSA) can present with primarily parkinsonian (MSA-P) or cerebellar dysfunction (MSA-C); however, autonomic dysfunction is an eventual unifying feature for all patients. Characteristically, there is poor response of parkinsonism or cerebellar ataxia to levodopa. Autonomic symptoms are typically orthostat- 
ic hypotension, male erectile dysfunction, and decreased sweating. Neuropathologic changes include glial cytoplasmic inclusions (comprising ubiquitin, tau, and $\alpha$-synuclein proteins) and degeneration in basal ganglia, cerebellum, autonomic nuclei in the brainstem, intermediolateral columns of the spinal cord, and Onuf's nucleus (for micturition and defecation) in the sacral S2 region of the spinal cord.

Constipation and fecal incontinence are classical features of MSA (46). A prominent disorder of esophageal dysmotility is demonstrated by videofluoroscopy and by manometry showing frequent, simultaneous, low-amplitude peristaltic waves. Fasting and postprandial antral and small bowel motility may be reduced (47).

Autonomic epilepsy and migraine. Autonomic epilepsy and migraine are infrequent causes of upper abdominal symptoms such as nausea and vomiting. Treatment is aimed at the underlying disorder and symptomatic remedies.

Amyotrophic lateral sclerosis. Amyotrophic lateral sclerosis (ALS) and progressive bulbar palsy result predominantly in weakness of the pharyngeal and respiratory muscles manifesting as dysphagia, respiratory difficulty, or aspiration. Physical examination reveals cranial nerve palsies, muscle fasciculations, and an exaggerated jaw jerk (pseudobulbar palsy). Videofluoroscopic swallow tests with liquids and solids are superior to a symptom-based functional rating scale to evaluate swallowing (48), assess aspiration, and guide nutritional support (oral or percutaneous gastrostomy; ref. 49). Cervical esophagostomy or cricopharyngeal myotomy may be required in cases with substantial cricopharyngeal muscle dysfunction.

In two series from Munich, 9 of 15 ALS patients had delayed colonic transit (50), and 15 of 18 had delayed gastric emptying (51) based on stable isotope breath test.

Post-polio syndrome. Post-polio syndrome affects $15 \%-80 \%$ of the 20 million polio survivors worldwide and manifests as exacerbation of symptoms, typically 15-30 years after the resolution of initial poliomyelitis (52). These patients experience muscle symptoms, pain, neuropathic sensory symptoms, and bulbar symptoms (53), specifically dysphagia and aspiration, especially if there was bulbar involvement during the initial attack.

Videofluoroscopy is useful for screening and monitoring progression of disease. Attention to the position of the patient's head during swallowing and alteration of food consistency to a semisolid state can decrease the prevalence of choking and aspiration.

Brainstem lesions. Brainstem lesions modulate gastric functions by affecting parasympathetic circuits (54): afferent vagal fibers, neurons of the nucleus tractus solitarius, and the efferent fibers originating in the DMV. Brainstem lesions can present with isolated gastrointestinal motor dysfunction or vomiting from distortion of the vomiting center on the floor of the fourth ventricle (55), even without increase in intracranial pressure (56). Compression of the brainstem and lower cranial nerves can cause neurogenic dysphagia in patients with Arnold-Chiari malformations (57).

The presence of more widespread autonomic dysfunction, particularly if vagal (Table 3) preganglionic sympathetic nerves are involved (as shown by anhidrosis on a thermoregulatory sweat test with sweating on the quantitative sudomotor axon reflex test reflecting intact postganglionic nerves; Table 4), necessitates searching for a CNS lesion.

\section{Autonomic system degenerations}

Autonomic function tests to identify the neuroanatomical basis for the diagnosis of these diseases are summarized in Tables 3 and 4, ref. 58 , and ref. 59 .

Pandysautonomia. Pandysautonomia is characterized by preganglionic or postganglionic lesions affecting both sympathetic and parasympathetic nerves. Gastrointestinal involvement (vomiting, paralytic ileus, constipation, or a chronic pseudo-obstruction; ref. 60) has been reported in acute, subacute, and congenital pandysautonomia (47). There are also reports of selective cholinergic dysautonomia resulting in gastrointestinal dysmotility after infectious mononucleosis (Epstein-Barr virus [EBV]) or influenza A $(61,62)$. Selective dysautonomia has been associated with autoantibodies to M3 muscarinic receptors (63). Chronic intestinal pseudo-obstruction may result from cytomegalovirus (CMV) infection of the myenteric plexus (64). In these conditions, antiganglionic acetylcholine receptor antibody may be present, usually in low titer, and the pathogenetic significance is uncertain (65).

Familial dysautonomia. Familial dysautonomia (also known as Riley-Day syndrome or hereditary sensory and autonomic neuropathy type III [HSAN III]) is an autosomal recessive disease resulting from poor development and progressive degeneration of the sensory and autonomic nervous system. Among the Ashkenazi Jewish population, 1 in 30 are carriers of mutations in the gene IKBKAP (also known as ELP1), resulting in mutation in the elongator protein 1 (ELP1) subunit of the highly conserved Elongator complex that results in altered functions of RNA polymerase II and histone acetylation in the nucleus, and alterations in diverse cellular functions such as cell migration and adhesion, intracellular trafficking, and the p53 activation mutant (66).

Signs and symptoms begin in infancy; presentations include abnormal respiratory responses to hypoxic and hypercarbic states, gastroesophageal reflux, vomiting crises, lack of overflow tears, profuse sweating, and postural hypotension. Infants suffer from poor muscle tone (hypotonia), feeding difficulties, poor growth, lack of tears, frequent lung infections, and difficulty maintaining body temperature. Younger children can exhibit breath-holding behavior leading to cyanosis, which usually stops by the age of 6 years.

Gastrointestinal involvement in adults includes oropharyngeal incoordination, poor suck, a tendency to drool, gastroesophageal reflux, intermittent vomiting (typically in reaction to physical or emotional stress), and preference for softer foods. Esophageal transit and gastric transit may be delayed and are associated with aspiration pneumonia (67), and reduced density of neurons in the myenteric plexus has been described (68). Esophageal motility may be profoundly disrupted, resulting in fluid levels and dilated esophagus (69). Neurologic manifestations may also be associated with increased circulating dopamine levels during vomiting episodes, suggesting activation of dopamine receptors in the chemoreceptor trigger zone (70). Indeed, carbidopa, which blocks the conversion of levodopa to dopamine in the systemic circulation, reduced frequency and intensity of the vomiting attacks (71).

Vomiting may be accompanied by "dysautonomic crisis" (hypertension, tachycardia, diffuse sweating, and personality change), which is typically responsive to diazepam as well as to countering of the adrenergic crisis with clonidine or dexmedeto- 
Table 3. Tests performed to assess parasympathetic control of viscera, normal values, and direct or indirect inference of gastrointestinal autonomic denervation

\begin{tabular}{|c|c|c|c|c|}
\hline Test & Function tested & Rationale & Normal values & Comments/pitfalls \\
\hline \multicolumn{5}{|l|}{ Cardiovascular } \\
\hline Heart rate variation with deep breathing & Parasympathetic & $\begin{array}{l}\text { Vagal afferents } \\
\text { stimulated by lung } \\
\text { stretch }\end{array}$ & $\begin{array}{l}\text { Age-related, 6-18 beats/ } \\
\text { min }\end{array}$ & $\begin{array}{l}\text { Best cardiovagal test available, but not a test of } \\
\text { abdominal vagus }\end{array}$ \\
\hline Supine/erect heart rate & Parasympathetic & $\begin{array}{l}\text { Vagal stimulation by } \Delta \\
\text { in central blood volume }\end{array}$ & & $\begin{array}{l}\text { Abnormal cardiovagal tests imply abdominal vagal } \\
\text { denervation in length-dependent neuropathies; } \\
\text { false negative if vagus injury at or below diaphragm }\end{array}$ \\
\hline Valsalva ratio (heart rate, max./min.) & Parasympathetic & $\begin{array}{l}\text { Vagal stimulation by } \Delta \\
\text { in central blood volume }\end{array}$ & $>1.5$ & $\begin{array}{l}\text { Abnormal cardiovagal tests imply abdominal vagal } \\
\text { denervation in length-dependent neuropathies; } \\
\text { false negative if vagus injury at or below diaphragm }\end{array}$ \\
\hline \multicolumn{5}{|c|}{ Abdominal vagus: pancreatic polypeptide response to } \\
\hline Modified sham feeding & Parasympathetic & $\begin{array}{l}\text { Stimulation of vagal } \\
\text { nuclei by sham feeding }\end{array}$ & $\begin{array}{l}>25 \mathrm{pg} / \mathrm{mL} \text { peak over } \\
\text { baseline }\end{array}$ & $\begin{array}{l}\text { Critically dependent on avoidance of swallowing } \\
\text { food during test }\end{array}$ \\
\hline \multicolumn{5}{|l|}{ Pupil responses to } \\
\hline Light & Parasympathetic & $\begin{array}{l}\text { Reflex involving } \\
\text { oculomotor nerve }\end{array}$ & $\begin{array}{l}\text { Latency } 0.2-0.3 \mathrm{~s} \text {, } \\
\text { constriction 2-4 mm }\end{array}$ & \\
\hline $\begin{array}{l}\text { Pharmacology: } \\
0.125 \% \text { pilocarpine }\end{array}$ & $\begin{array}{c}\text { Denervation } \\
\text { hypersensitivity }\end{array}$ & Parasympathetic & $<0.5 \mathrm{~mm}$ constriction & \\
\hline $0.1 \%$ epinephrine & & & No change & \\
\hline $5 \%$ cocaine & & Sympathetic & $>1.5 \mathrm{~mm}$ dilation & \\
\hline
\end{tabular}

Penis and urinary bladder

$\begin{array}{llr}\text { Nocturnal penile tumescence } & \text { Pelvic parasympathetic } & \text { Integrity of S2-4 } \\ \begin{array}{l}\text { Cystometrographic response to } \\ \text { cholinergic agonist }\end{array} & \text { Pelvic parasympathetic } & \begin{array}{c}\text { Increased intravesical } \\ \text { pressure in denervation } \\ \text { supersensitivity }\end{array}\end{array}$

Plethysmographic technique requiring special facilities

Tests parasympathetic supply to bladder, not bowel

Adapted with permission from Gastroenterology (Table 1 in ref. 58, copyright 1994 Elsevier), and with permission from Lippincott-Raven Publishers (Table 5 in ref. 59).

midine, which activate brain presynaptic $\alpha_{2}$-adrenoceptors, inhibiting the release of norepinephrine from synaptic vesicles.

In patients who suffer from recurrent aspiration pneumonia or feeding problems, surgical management such as fundoplication or placement of a gastric feeding tube may be required (72).

Idiopathic orthostatic hypotension and pure autonomic failure. Idiopathic orthostatic hypotension is a rare form of autonomic failure unassociated with neurologic deficits other than cell loss in intermediolateral columns of the spinal cord and sympathetic ganglia (73). Cardiovascular and sudomotor abnormalities usually precede motor dysfunction of the gut, such as esophageal dysmotility, gastric stasis, alteration in bowel movements, and fecal incontinence $(74,75)$. The precise site of the lesion causing the gut dysmotility is unknown. Some reports document Lewy bodies in distal axons (73).

Pure autonomic failure results from widespread neuronal degeneration in the preganglionic sympathetic intermediolateral column and paravertebral ganglia leading to loss of peripheral adrenergic innervation. It has been associated with gastrointestinal complications such as constipation or intestinal pseudo-obstruction (76), in addition to micturition disorders (77).

Postural orthostatic tachycardia syndrome. Postural orthostatic tachycardia syndrome (POTS) is a form of orthostatic intolerance, particularly in younger female adults, with exaggerated heart rate increase in response to postural change with absence of orthostatic hypotension (sustained drop in blood pressure of at least 20/10 $\mathrm{mmHg}$ within 3 minutes of assuming upright posture). It is important to exclude dehydration, other medical conditions, medications, and dietary influences on blood pressure and pulse rate. POTS may be a manifestation of a mild form of acute autonomic neuropathy (78).

About one-third of patients with POTS have gastrointestinal manifestations such as nausea, vomiting, bloating, or constipation $(79,80)$. In addition, comorbidities associated with POTS include the hypermobility form of Ehlers-Danlos syndrome, fibromyalgia, chronic fatigue, interstitial cystitis (81), and functional gastrointestinal disorders (82). A hyperadrenergic variant of POTS may be associated with mast cell activation disorders (MCADs) that present with episodic "attacks" of flushing, lightheadedness, dizziness, dyspnea, nausea, headache, diarrhea, and/or syncope. Diagnostic markers of MCADs are heparin, prostaglandin $\mathrm{D}_{2}$, histamine, and chromogranin A (83).

Patient management is directed at the underlying POTS and symptomatic relief for the gastrointestinal manifestations (81).

Myasthenia gravis. Myasthenia gravis is characterized by fatigable weakness due to failure of neuromuscular junction trans- 
Table 4. Tests performed to assess sympathetic control of viscera, normal values, and direct or indirect inference of gastrointestinal autonomic denervation

\begin{tabular}{|c|c|c|c|c|}
\hline Test & Function tested & Rationale & Normal values & Comments/pitfalls \\
\hline \multicolumn{5}{|l|}{ Sweat tests } \\
\hline $\begin{array}{l}\text { Thermoregulatory sweat test } \\
\text { (\% surface area of anhidrosis) }\end{array}$ & $\begin{array}{c}\text { Preganglionic and } \\
\text { postganglionic cholinergic }\end{array}$ & $\begin{array}{l}\text { Stimulation of hypothalamic } \\
\text { temperature control centers }\end{array}$ & $\begin{array}{c}\% \text { Surface area of anhidrosis: } \\
\qquad \mathrm{M}, 0 \% ; \mathrm{F},<3 \%\end{array}$ & Cumbersome, whole-body test \\
\hline $\begin{array}{l}\text { Quantitative sudomotor axon } \\
\text { reflex test (sweat output, } \\
\text { latency) }\end{array}$ & Postganglionic cholinergic & $\begin{array}{c}\text { Antidromic stimulation of peripheral } \\
\text { (postganglionic sympathetic fiber) } \\
\text { by axonal reflex }\end{array}$ & $\begin{array}{l}\text { Sweat output }\left(\mu \mathrm{L} / \mathrm{cm}^{3}\right) \\
\text { Forearm: } \mathrm{M}, 0.76-5.51 ; \mathrm{F}, 0.34-1.33 \\
\text { Foot: } \mathrm{M}, 0.92-5.73 ; \mathrm{F}, 0.25-1.95 \\
\text { Latency (min) } \\
\text { Forearm: } \mathrm{M}, 1-2.4 ; \mathrm{F}, 0.9-1.9 \\
\text { Foot: } \mathrm{M}, 1-2.7 ; \mathrm{F}, 1-2.8\end{array}$ & Needs specialized facilities \\
\hline
\end{tabular}

Cardiovascular tests

\begin{tabular}{|c|c|c|c|c|}
\hline $\begin{array}{l}\text { Heart rate and BP responses } \\
\text { to orthostatic tilt }\end{array}$ & Adrenergic & Baroreceptor reflex & $\begin{array}{l}\text { Response to } 80^{\circ} \text { tilt: systolic BP } \\
<25 \mathrm{mmHg} \text {; diastolic BP }<15 \mathrm{mmHg}\end{array}$ & $\begin{array}{l}\text { Impaired if intravascular volume } \\
\text { is reduced }\end{array}$ \\
\hline \multicolumn{5}{|l|}{ Plasma norepinephrine } \\
\hline Response to postural changes & Postganglionic adrenergic & Baroreceptor stimulation & $\begin{array}{c}\text { Supine: } 70-750 \mathrm{pg} / \mathrm{mL} ; \\
\text { standing: } 200-1700 \mathrm{pg} / \mathrm{mL}\end{array}$ & $\begin{array}{l}\text { Moderate sensitivity, impaired } \\
\text { if intravascular volume reduced }\end{array}$ \\
\hline $\begin{array}{l}\text { Response to i.v. edrophonium } \\
\text { (anticholinesterase) }\end{array}$ & Postganglionic adrenergic & $\begin{array}{l}\text { Drug "stimulates" postganglionic } \\
\text { fiber at prevertebral ganglia }\end{array}$ & $\begin{array}{l}>35 \% \text { increase above baseline } \\
\text { within 2-8 minutes }\end{array}$ & $\begin{array}{l}\text { False negatives by contributions } \\
\text { to plasma norepinephrine } \\
\text { from many organs }\end{array}$ \\
\hline
\end{tabular}

Adapted with permission from Gastroenterology (Table 1 in ref. 58, copyright 1994 Elsevier), and with permission from Lippincott-Raven Publishers (Table 5 in ref. 59).

mission caused by antibodies against the acetylcholine receptor. This may manifest with symptoms such as dysphagia (sometimes accompanied by dysphonia). Abnormal esophageal motility may be identified by high-resolution manometry showing fatigue as reduced-amplitude contractions with repetitive swallows, and increased amplitude with administration of the anticholinesterase edrophonium (84). There is also autonomic dysfunction such as pupillary fatigability in myasthenia gravis, and sometimes gastrointestinal symptoms such as gastroparesis (85). Paraneoplastic complications in patients with thymoma and myasthenia gravis include intestinal pseudo-obstruction (86) or hypogammaglobulinemia with gastrointestinal CMV, herpes simplex, and Candida infections (87).

\section{Spinal cord lesions}

Spinal cord injury. Gastrointestinal motility disturbances such as dysphagia may be short-lived soon after acute spinal cord injury, and ileus or acalculous cholecystitis may occur after acute cervical spinal cord injury (88). The acute abdomen may present, not with rigidity or absent bowel sounds, but with dull or poorly localized pain, vomiting, or restlessness, with tenderness, fever, and leukocytosis in up to $50 \%$ of patients (89). Lack of recognition of the acute abdominal condition may lead to increased mortality.

In contrast, chronic bowel dysfunctions occur in $27 \%-62 \%$ of patients with spinal cord injury, most commonly constipation, distention, abdominal pain, rectal bleeding, hemorrhoids, fecal incontinence, and autonomic hyperreflexia. Gallstones occur in $17 \%-31 \%$ of patients with spinal cord injury (89). Disorders of upper gastrointestinal motility are uncommon in the chronic phase after injury, whereas colonic and anorectal dysfunctions are common and result from interruption of supraspinal control of the sacral parasympathetic supply to the colon (with reduced postprandial motor responses; ref. 90), pelvic floor, and anal sphincters, leading to defecation disorders or fecal incontinence.

Patients rely on reflex rectal stimulation for stool evacuation and a combination of laxatives, bulking agents, anal massage, manual evacuation, and scheduled enemas or transanal irrigation (91). Randomized, double-blind studies have demonstrated effectiveness of neostigmine, which increases cholinergic tone, combined with glycopyrrolate, an anticholinergic agent with minimal activity in the colon that reduces extracolonic side effects. Computerized electrical stimulation of the sacral anterior roots (92, 93) may restore normal function to the pelvic colon and anorectal sphincters when combined with S2 to S4 posterior sacral rhizotomy to avoid autonomic dysreflexia. If these measures are ineffective and severe constipation persists, a colostomy reduces time for bowel care and allows decubitus ulcers to heal.

Multiple sclerosis. Motility disturbances in multiple sclerosis (MS) are more frequent in the lower than in the upper gut. Bowel and bladder problems affect over $50 \%$ of people with MS, impacting quality of life, social interactions, and health care costs. Severe constipation (94), urinary bladder dysfunction, and fecal incontinence often occur together. In one study of 167 patients, $74.4 \%$ had bladder problems, $48.9 \%$ had functional constipation, and $31.9 \%$ had fecal incontinence (95). These result from impaired function of the supraspinal or descending pathways that control Onuf's nucleus (sacral parasympathetic outflow). As in Parkinson disease, bowel symptoms predate the diagnosis among many patients with MS, based on a 14-year cohort study (96).

Anorectal manometry $(97,98)$ is helpful to differentiate anal sphincter hypotonia, rectal hyposensitivity (both causes of incontinence), and pelvic floor dyssynergia as the cause of constipation, 
which may be complicated by "overflow" incontinence. Abnormal rectal compliance correlates with overall disability (99) in MS. Transanal irrigation or lower bowel stimulation (as in patients with spinal cord injury) may be required to relieve the constipation and avoid incontinence episodes. In patients with limited disability and a nonprogressive disease, biofeedback retraining may be helpful for constipation or fecal incontinence (100).

Neuromyelitis optica. The area postrema (including morphologic evidence of aquaporin-4 autoimmunity) may be a selective target of the disease process in neuromyelitis optica. Clinical reports (101) document nausea and vomiting preceding episodes of optic neuritis and transverse myelitis.

\section{Peripheral neuropathy}

Acute peripheral neuropathy. Acute viral infections may result in dysautonomia as described above. Guillain-Barré syndrome is the most prevalent acute peripheral motor neuropathy with visceral involvement (e.g., gastric distention or adynamic ileus) in association with diverse infections or toxins including herpes zoster, EBV, Borrelia burgdorferi (Lyme disease), botulism B toxin, Helicobacter pylori (102), treatment with anti-CTL4 antibodies (103), and, more recently, Zika virus (104) and SARS-CoV-2 infection (105). The site of the neurologic lesion causing the gut manifestations is uncertain. Treatment is supportive and in addition to management of the Guillain-Barré syndrome, such as with plasmapheresis.

Chronic peripheral neuropathy. Chronic peripheral neuropathy is the most prevalent neurologic disorder resulting in gastrointestinal motor dysfunction.

Diabetes mellitus. Epidemiologic studies of adults with diabetes mellitus (36.5\% of whom were on insulin treatment) showed higher prevalence of upper gastrointestinal symptoms in a US national sample (106), and higher prevalence of constipation, with or without laxative use, in a cohort of 138 type 1 diabetics but not in 217 type 2 diabetics in Olmsted County, Minnesota (107), compared with age- and sex-matched controls. Patients with constipation tended to be taking some medications that cause the symptoms or to have bladder symptoms (107).

Impaired motility throughout the gut in diabetes mellitus results in gastroparesis (with antral hypomotility and pylorospasm), accelerated gastric emptying, reduced gastric accommodation, diarrhea, constipation, and fecal incontinence $(5,108)$. These features are associated with "autovagotomy" (reduction in unmyelinated axons) and loss of the interstitial cells of Cajal (pacemaker cells). The latter may result from imbalance in the local CD206-positive macrophages that normally protect cells from the effects of oxidative stress (5). Hypoglycemic agents such as amylin and GLP-1 agonists (particularly short-acting agents) induce gastroparesis $(109,110)$.

Constipation among community diabetics was associated equally with slow transit, normal transit, or pelvic floor dysfunction (111). Fecal incontinence may result from abnormal rectal sensation or weakness of the internal anal sphincter (sympathetic denervation) or external anal sphincter (sacral parasympathetic neuropathy).

Diarrhea may result from several mechanisms (112) such as intake of artificial sweeteners such as sorbitol, adverse effect of metformin (with bile acid malabsorption), bacterial overgrowth due to small bowel stasis, rapid transit from uncoordinated small bowel motility, or, rarely, associated gluten-sensitive enteropathy or pancreatic exocrine insufficiency.

Amyloidosis. Gastrointestinal disease in amyloidosis results from either mucosal or neuromuscular infiltration, or extrinsic autonomic neuropathy. A retrospective series (113) reported that $3.2 \%$ of 2334 patients with amyloidosis had biopsy-proven gastrointestinal amyloidosis. Amyloid neuropathy may lead to dysphagia, constipation, diarrhea, and steatorrhea. In manometric studies of the esophagus (114) or small bowel $(115,116)$, earlier stages of gastrointestinal amyloidosis were characterized by motor incoordination consistent with neural involvement, and later stages were characterized by low amplitude, reflecting myopathy due to amyloid infiltration of muscle. Familial amyloidosis (e.g., hereditary transthyretin amyloidosis) may also affect small bowel motility (117).

Advanced therapies for amyloidosis (autologous or allogeneic stem cell transplantation in combination with cytotoxic therapy for systemic amyloidosis, or liver transplant for transthyretin amyloidosis) may result in substantial symptomatic improvement $(118,119)$ in gastrointestinal amyloidosis. Antisense oligonucleotide-based drugs and RNA interference therapies are also used in treatment of hereditary transthyretin amyloidosis (120).

Paraneoplastic neuropathy. Gastrointestinal symptoms may occur in association with small-cell carcinoma of the lung or pulmonary carcinoid or neuroendocrine (121) tumors. Symptoms include constipation, gastroparesis, intestinal pseudo-obstruction, and esophageal spasm or achalasia (122).

There are circulating IgG antibodies (e.g., ANNA-1 or anti$\mathrm{Hu}$ ) directed against enteric neuronal nuclei, suggesting that the enteric plexus is the major target of this paraneoplastic phenomenon $(123,124)$. Other autoantibodies (anti-CRMP-5 [also known as anti-CV-2] and anti-ganglionic acetylcholine receptor) (125) associated with lung cancer or thymoma result in gastroparesis or constipation. Several patients have shown evidence of a more extensive neuropathologic process (126).

A chest $x$-ray is frequently normal in these patients. A chest CT scan or whole-body fluorodeoxyglucose positron emission tomography (FDG-PET) or FDG-PET/CT aids detection of tumor or metastases (127). Immunomodulatory treatment before, during, or after antineoplastic therapy may provide benefit for the paraneoplastic neuropathy.

Porphyria. Gastrointestinal involvement is common in porphyria and usually presents with abdominal pain, nausea, vomiting, and constipation $(128,129)$. Porphyria is associated with demyelination of peripheral and autonomic nerves; dilation and impaired motor function occur in any segment of the intestinal tract. Effects of porphyria on the enteric nervous system have not yet been described. The diverse syndromes and management are described elsewhere (130).

Neurofibromatosis. Children with neurofibromatosis type 1 frequently have constipation (131), which can be associated with enlarged rectal diameter and prolonged colonic transit time. Although there are rare reports of motility disorders $(132,133)$ with neurofibromatosis, it is essential to exclude mass lesions or obstruction. In addition, up to $25 \%$ of neurofibromatosis type 1 patients (134) develop intra-abdominal neoplastic manifestations, including neurogenic tumors (commonly plexiform neurofibromas and malignant peripheral nerve sheath tumors), tumors origi- 
nating from the interstitial cells of Cajal (hyperplasia, gastrointestinal stromal tumors), neuroendocrine tumors, embryonal tumors (rhabdomyosarcoma), or rectal neuroendocrine tumors (135).

Lipomatosis of nerve. Among 10 patients with lipomatosis of nerve of the lumbosacral plexus and/or sciatic nerve, 3 patients had colonic diverticulosis at a young age, with involvement of the sacral nerves innervating the sigmoid colon. One had reduced colonic motility in response to a meal with preserved stimulation by i.v. neostigmine and morphologically normal myenteric neurons, consistent with extrinsic denervation (136).

HIV neuropathy. Gastrointestinal symptoms may result from infections secondary to the immunodeficiency. In addition, chronic diarrhea may result from increased extrinsic parasympathetic activity (137) to the gut, or damage to adrenergic fibers within the enteric plexuses, or as an adverse event to nelfinavir-based combination therapy (138). In a nonblinded, randomized, crossover study of 12 patients with AIDS-related chronic diarrhea unresponsive to loperamide, the enkephalinase inhibitor racecadotril (100-300 mg, orally, 3 times daily) was superior to the short-acting somatostatin analog octreotide (50-150 $\mu \mathrm{g}$, subcutaneously, 3 times daily) during 1 week of treatment. Racecadotril also improved diarrhea relative to baseline (139). Adsorbent drugs such as attapulgite were not superior to placebo (140).

Autoimmune neuropathies due to antibodies against neuronal receptors. Autoantibodies directed against specific neural antigens, including ion channels, may be associated with gut motility disorders including esophageal dysmotility, slow transit constipation, and chronic intestinal pseudo-obstruction. Ganglionic receptor-binding antibodies have also been found in a subset of patients with idiopathic, paraneoplastic, or diabetic autonomic neuropathy, and in idiopathic gastrointestinal dysmotility (141, 142). The antibody titer correlated with more severe autonomic dysfunction. This autoimmune form of gastrointestinal dysmotility has been replicated in an animal model (143).

\section{Muscle diseases causing gut dysmotility}

Duchenne and Becker muscular dystrophies, polymyositis, and dermatomyositis. Duchenne and Becker muscular dystrophies, polymyositis, and dermatomyositis have been associated rarely with gastroparesis $(144,145)$. These skeletal muscle diseases and inclusion body myositis (146) more often affect pharyngoesophageal swallowing. Manometry shows low-amplitude or absent pharyngeal contractions and decreased upper esophageal sphincter pressures. Elevated serum creatine kinase (CK) and lactate dehydrogenase $(\mathrm{LDH})$ reflect skeletal muscle injury.

Hollow visceral myopathy and mitochondrial neurogastrointestinal encephalomyopathy. Among patients presenting with hollow visceral myopathy (a myopathic form of chronic intestinal pseudo-obstruction that can be sporadic or familial), the finding of an external ophthalmoplegia and ptosis, or with deafness, should alert the gastroenterologist to the possible diagnosis of mito- chondrial neurogastrointestinal encephalomyopathy (MNGIE) (147-149). MNGIE is also associated with multiple small intestinal diverticula with bacterial overgrowth and malabsorption, peripheral neuropathy, leukoencephalopathy due to demyelination of nerve fibers, and skeletal muscle injury, with ragged red fibers reflecting megamitochondria on skeletal muscle biopsy (elevated CK and LDH). MNGIE is associated with upward of 50 mutations in TYMP genes encoding thymidine phosphorylase (150).

Allogeneic stem cell transplantation (151) has been proposed as an early treatment for MNGIE while patients are still relatively healthy. However, more recent experience has shown that hematopoietic or liver transplantation does not benefit the intestinal pathologic process, especially in patients with more advanced disease $(152,153)$.

Myotonic dystrophy. Patients with myotonic dystrophy may have dysphagia, gastroesophageal reflux, cholecystectomy at a young age (154), or megacolon (155); in the autosomal dominant type 1 form, $70 \%$ of patients presented with these manifestations as well as malnutrition and fecal incontinence in childhood or adolescence (156). In myotonic dystrophy type 1 , there are also reports of chronic intestinal pseudo-obstruction and megacolon associated with smooth muscle $\alpha$-actin deficiency and inflammation of the myenteric plexus (157).

Anal sphincter dysfunction is consistent with an expression of myopathy, muscular atrophy, and neural abnormalities.

Myopathic disorders are associated with low-amplitude contractions at affected levels of the gut. They may be complicated by bacterial overgrowth, small bowel diverticula, pneumatosis cystoides intestinalis, and spontaneous pneumoperitoneum. Skeletal muscle electromyography or biopsy may be needed to establish the nature of the generalized neuromuscular disorder, as in mitochondrial myopathy.

\section{Conclusion}

Although symptoms such as dysphagia, dyspepsia, constipation, and fecal incontinence are frequently encountered in the community, neurologic causes for these symptoms are relatively rare. Whereas the presence of established neurologic conditions such as Parkinson disease, peripheral neuropathy, and multiple sclerosis can alert the clinician to the association with gut manifestations, it is helpful, in taking the patient's history, to inquire about peripheral sensory and motor, and autonomic, symptoms to explore the possibility of neuropathic gastrointestinal disorders.

\section{Acknowledgments}

The author thanks Cindy Stanislav for excellent secretarial assistance. MC's studies on gastroparesis are supported by grant R01DK122280 from the NIH.

Address correspondence to: Michael Camilleri, Mayo Clinic, Charlton Building, Room 8-110, 200 First Street SW, Rochester, Minnesota 55905, USA. Phone: 507.266.2305; Email: camilleri. michael@mayo.edu.
1. Kreulen DL, Szurszewski JH. Reflex pathways in the abdominal prevertebral ganglia: evidence for a colo-colonic inhibitory reflex. J Physiol. 1979;295:21-32.

2. Langley JN, Anderson HK. On the innervation of the pelvic and adjoining viscera: Part I. The lower portion of the intestine. J Physiol. 1895;18(1-2):67-105.

3. Szurszewski JH, Krier J. Sympathetic regulation of gastrointestinal motility. In: Dyck PJ, et al., eds. Peripheral Neuropathy. 2nd ed. WB Saunders; 1984:265-284.

4. Camilleri, M. Autonomic regulation of gastrointestinal motility. In: Low PA, ed. Clinical Autonomic Disorders: Evaluation and Management. 2nd 
ed. Lippincott-Raven Publishers; 1997:135-145.

5. Camilleri M, et al. Gastroparesis. Nat Rev Dis Primers. 2018;4(1):41.

6. Read NW, Houghton LA. Physiology of gastric emptying and pathophysiology of gastroparesis. Gastroenterol Clin North Am. 1989;18(2):359-373.

7. Reynolds BJ, Eliasson SG. Colonic pseudoobstruction in patients with stroke. Ann Neurol. 1977;1(3):305

8. Rosa-E-Silva L, et al. Clinical, radiologic, and manometric characteristics of chronic intestinal dysmotility: the Stanford experience. Clin Gastroenterol Hepatol. 2006;4(7):866-873.

9. Stanghellini V, et al. Natural history of chronic idiopathic intestinal pseudo-obstruction in adults: a single center study. Clin Gastroenterol Hepatol. 2005;3(5):449-458.

10. Stanghellini V, et al. Chronic intestinal pseudoobstruction: manifestations, natural history and management. Neurogastroenterol Motil. 2007;19(6):440-452.

11. Camilleri M, et al. Chronic constipation. Nat Rev Dis Primers. 2017;3:17095.

12. Metcalf AM, et al. Simplified assessment of segmental colonic transit. Gastroenterology. 1987;92(1):40-47.

13. Manabe N, et al. Lower functional gastrointestinal disorders: evidence of abnormal colonic transit in a 287 patient cohort. Neurogastroenterol Motil. 2010;22(3):293.

14. Bharucha AE, Rao SS. An update on anorectal disorders for gastroenterologists. Gastroenterology. 2014;146(1):37-45.

15. Martino R, et al. Dysphagia after stroke: incidence, diagnosis, and pulmonary complications. Stroke. 2005;36(12):2756-2763.

16. Arnold M, et al. Dysphagia in acute stroke: incidence, burden and impact on clinical outcome. PLoS One. 2016;11(2):e0148424.

17. Geeganage $\mathrm{C}$, et al. Interventions for dysphagia and nutritional support in acute and subacute stroke. Cochrane Database Syst Rev. 2012;10:CD000323.

18. Duncan S, et al. Interventions for oropharyngeal dysphagia in acute and critical care: a systematic review and meta-analysis. Intensive Care Med. 2020;46(7):1326-1338.

19. Li J, et al. Incidence of constipation in stroke patients: a systematic review and meta-analysis. Medicine (Baltimore). 2017;96(25):e7225.

20. Cheng J, et al. Poststroke constipation is associated with impaired rectal sensation. Am J Gastroenterol. 2020;115(1):105-114.

21. $\mathrm{Yi} \mathrm{JH}$, et al. Bowel function in acute stroke patients. Ann Rehabil Med. 2011;35(3):337-343.

22. $\mathrm{Wu} \mathrm{JH}$, et al. Incidence of serious upper and lower gastrointestinal events in older adults with and without Alzheimer's disease. J Am Geriatr Soc. 2011;59(11):2053-2061.

23. Farlow M, et al. Safety and tolerability of donepezil $23 \mathrm{mg}$ in moderate to severe Alzheimer's disease. BMC Neurol. 2011;11:57.

24. Darreh-Shori T, Jelic V. Safety and tolerability of transdermal and oral rivastigmine in Alzheimer's disease and Parkinson's disease dementia. Expert Opin Drug Saf. 2010;9(1):167-176.

25. Rietdijk CD, et al. Exploring braak's hypothesis of parkinson's disease. Front Neurol. 2017;8:37.
26. Travagli RA, et al. Parkinson disease and the gut: new insights into pathogenesis and clinical relevance. Nat Rev Gastroenterol Hepatol. 2020;17(11):673-5685.

27. Liu B, et al. Vagotomy and Parkinson disease: a Swedish register-based matched-cohort study. Neurology. 2017;88(21):1996-2002.

28. Edwards LL, et al. Gastrointestinal symptoms in Parkinson's disease. Mov Disord. 1991;6(2):151-156.

29. Edwards L, et al. Gastrointestinal symptoms in Parkinson disease: 18-month follow-up study. Mov Disord. 1993;8(1):83-86.

30. Cersósimo MG, et al. Hyposialorrhea as an early manifestation of Parkinson disease. Auton Neurosci. 2009;150(1-2):150-151.

31. Hinkle JT, et al. Dopamine transporter availability reflects gastrointestinal dysautonomia in early Parkinson disease. Parkinsonism Relat Disord. 2018;55:8-14.

32. Cersosimo MG, et al. Gastrointestinal manifestations in Parkinson's disease: prevalence and occurrence before motor symptoms. J Neurol. 2013;260(5):1332-1338.

33. Khoshbin $\mathrm{K}$, et al. Cohort study in parkinsonism: delayed transit, fast gastric emptying, and prodromal dysmotility. Nat Rev Gastroenterol Hepatol. 2020;17(11):673-685.

34. Fasano A, et al. Gastrointestinal dysfunction in Parkinson's disease. Lancet Neurol. 2015;14(6):625-639.

35. Postma AG, et al. Radiotherapy to the salivary glands as treatment of sialorrhea in patients with Parkinsonism. Mov Disord. 2007;22(16):2430-2435.

36. Triadafilopoulos G, et al. Precision GERD management for the 21st century. Dis Esophagus. 2017;30(9):1-6.

37. van Hooren MR, et al. Treatment effects for dysphagia in Parkinson's disease: a systematic review. Parkinsonism Relat Disord. 2014;20(8):800-807.

38. Manor Y, et al. Video-assisted swallowing therapy for patients with Parkinson's disease. Parkinsonism Relat Disord. 2013;19(2):207-211.

39. Pfeiffer RF, et al. Clinical implications of gastric complications on levodopa treatment in Parkinson's disease. Parkinsonism Relat Disord. 2020;76:63-71.

40. Heetun ZS, Quigley EMM. Gastroparesis and Parkinson's disease: a systematic review. Parkinsonism Relat Disord. 2012;18(5):433-440.

41. Kaut O, et al. Transcutaneous vagal nerve stimulation improves gastroenteric complaints in Parkinson's disease patients. NeuroRehabilitation. 2019;45(4):449-451.

42. Zanzaglia R, et al. Macrogol for the treatment of constipation in Parkinson's disease. A randomized placebo-controlled study. Mov Disord. 2007;22(9):1239-1244.

43. Ondo WG, et al. Placebo-controlled trial of lubiprostone for constipation associated with Parkinson disease. Neurology. 2012;78(21):1650-1654

44. Edwards LL, et al. Defecatory function in Parkinson's disease: response to apomorphine. Ann Neurol. 1993;33(5):490-493.

45. Hauser RA, et al. Targeting neurons in the gastrointestinal tract to treat Parkinson's disease. Clin Parkinson Rel Disord. 2019;1:2-7.
46. Shy GM, Drager GA. A neurological syndrome associated with orthostatic hypotension: a clinicalpathologic study. Arch Neurol. 1960;2:511-527.

47. Camilleri M. Disorders of gastrointestinal motility in neurologic diseases. Mayo Clin Proc. 1990;65(6):825-846.

48. Chapin JL, et al. Diagnostic utility of the amyotrophic lateral sclerosis Functional Rating Scale-Revised to detect pharyngeal dysphagia in individuals with amyotrophic lateral sclerosis. PLoS One. 2020;15(8):e0236804.

49. Elbe P, et al. Effectiveness of percutaneous endoscopic gastrostomy in amyotrophic lateral sclerosis. Minerva Gastroenterol Dietol. 2020;66(3):219-224.

50. Toepfer M, et al. Delayed colonic transit times in amyotrophic lateral sclerosis assessed with radio-opaque markers. Eur J Med Res. 1997;2(11):473-476

51. Toepfer M, et al. Noninvasive (13)C-octanoic acid breath test shows delayed gastric emptying in patients with amyotrophic lateral sclerosis. Digestion. 1999;60(6):567-571.

52. Oluwasanmi OJ, et al. Postpolio syndrome: a review of lived experiences of patients. Int J Appl Basic Med Res. 2019;9(3):129-134.

53. Kay L, et al. Neurological symptoms in Danes with a history of poliomyelitis: lifelong follow-up of late symptoms, their association with initial symptoms of polio, and presence of postpolio syndrome. Eur Neurol. 2018;80(5-6):295-303.

54. Travagli RA, et al. Brainstem circuits regulating gastric function. Annu Rev Physiol. 2006;68:279-305

55. Wood JR, et al. Brainstem tumor presenting as an upper gut motility disorder. Gastroenterology. 1985;89(6):1411-1414.

56. Mann SD, et al. Intractable vomiting due to a brainstem lesion in the absence of neurological signs or raised intracranial pressure. Gut. 1998;42(6):875-877.

57. Elta GH, et al. Esophageal dysphagia as the sole symptom in type I Chiari malformation. Dig Dis Sci. 1996;41(3):512-515.

58. Camilleri M, Ford MJ. Functional gastrointestinal disease and the autonomic nervous system: a way ahead? Gastroenterology. 1994;106(4):1114-1118.

59. Prather CM, Camilleri M. Gastrointestinal dysfunction: approach to management. In: Low PA, ed. Clinical Autonomic Disorders: Evaluation and Management. 2nd ed. Lippincott-Raven Publishers; 1997:597-612.

60. Suarez GA, et al. Idiopathic autonomic neuropathy: clinical, neurophysiologic, and follow-up studies on 27 patients. Neurology. 1994;44(9):1675-1682.

61. Vassallo M, et al. Gastrointestinal motor dysfunc tion in acquired selective cholinergic dysautonomia associated with infectious mononucleosis. Gastroenterology. 1991;100(1):252-258.

62. Lukkarinen H, Peltola V. Influenza A induced acute autonomic neuropathy in an adolescent. Pediatr Neurol. 2010;43(6):425-426.

63. Palma J-A, et al. Autoantibodies blocking M3 muscarinic receptors cause postganglionic cholinergic dysautonomia. Ann Neurol. 2020;88(6):1237-1243.

64. Sonsino E, et al. Intestinal pseudoobstruction 
related to cytomegalovirus infection of the myenteric plexus (Letter to the Editor). $N$ Engl J Med.1984;311(3):196-197.

65. Sandroni P, Low PA. Other autonomic neuropathies associated with ganglionic antibody. Auton Neurosci. 2009;146(1-2):13-17.

66. Rubin BY, Anderson SL. IKBKAP/ELP1 gene mutations: mechanisms of familial dysautonomia and gene-targeting therapies. Appl Clin Genet. 2017;10:95-103.

67. Krausz Y, et al. Scintigraphic evaluation of esophageal transit and gastric emptying in familial dysautonomia. Eur J Radiol. 1994;18(1):52-56.

68. Bar-Shai A, et al. Decreased density of ganglia and neurons in the myenteric plexus of familial dysautonomia patients. J Neurol Sci. 2004;220(1-2):89-94.

69. Palma J-A, et al. Neurogenic dysphagia with undigested macaroni and megaesophagus in familial dysautonomia. Clin Auton Res. 2018;28(1):125-126.

70. Norcliffe-Kaufmann LJ, et al. Cyclic vomiting associated with excessive dopamine in Riley-day syndrome. JClin Gastroenterol. 2013;47(2):136-138.

71. Norcliffe-Kaufmann L, et al. Hyperdopaminergic crises in familial dysautonomia: a randomized trial of carbidopa. Neurology. 2013;80(17):1611-1617.

72. Axelrod FB, et al. Fundoplication and gastrostomy in familial dysautonomia. JPediatr. 1991;118(3):388-394.

73. Hague K, et al. The distribution of Lewy bodies in pure autonomic failure: autopsy findings and review of the literature. Acta Neuropathol. 1997;94(2):192-196.

74. Camilleri M, Malagelada J-R. Abnormal intestinal motility in diabetics with gastroparesis. Eur J Clin Invest. 1984;14(6):420-427.

75. Thatcher BS, et al. Altered gastroesophageal motility in patients with idiopathic orthostatic hypotension. Cleve Clin J Med. 1987;54(2):77-82.

76. Yamanaka Y, et al. Chronic intestinal pseudoobstruction as the initial feature of pure autonomic failure. J Neurol Neurosurg Psychiatry. 2006;77(6):800

77. Sakakibara R, et al. Micturitional disturbance in pure autonomic failure. Neurology. 2000;54(2):499-501.

78. Schondorf R, Low PA. Idiopathic postural orthostatic tachycardia syndrome: an attenuated form of acute pandysautonomia? Neurology. 1993;43(1):132-137.

79. Low PA, et al. Comparison of the postural tachycardia syndrome (POTS) with orthostatic hypotension due to autonomic failure. J Auton Nerv Syst. 1994;50(2):181-188.

80. Park K-J, et al. Gastric emptying in postural tachycardia syndrome: a preliminary report. Clin Auton Res. 2013;23(4):163-167.

81. DiBaise JK, et al. Postural tachycardia syndrome (POTS) and the GI tract: a primer for the gastroenterologist. Am J Gastroenterol. 2018;113(10):1458-1467.

82. Tai FWD, et al. Functional gastrointestinal disorders are increased in joint hypermobility-related disorders with concomitant postural orthostatic tachycardia syndrome [published online August 16, 2020]. Neurogastroenterol Motil. https://doi. org $/ 10.1111 /$ nmo.13975.
83. Afrin LB, et al. Characterization of mast cell activation syndrome. Am J Med Sci. 2017;353(3):207-215

84. Torres-Barrera G, et al. High-resolution esophageal manometry in myasthenia gravis. ACG Case Rep J. 2020;7(3):e00340.

85 . Vernino S, et al. Myasthenia gravis with autoimmune autonomic neuropathy. Auton Neurosci. 2001;88(3):187-192.

86. Anderson NE, et al. Intestinal pseudo-obstruction, myasthenia gravis, and thymoma. Neurology. 1996;47(4):985-987.

87. Gupta S, et al. Watery diarrhea in a patient with myasthenia gravis, thymoma, and immunodeficiency. Am J Gastroenterol. 1985;80(11):877-881.

88. Wolf C, Meiners TH. Dysphagia in patients with acute cervical spinal cord injury. Spinal Cord. 2003;41(6):347-353.

89. Ebert E. Gastrointestinal involvement in spinal cord injury: a clinical perspective. J Gastrointestin Liver Dis. 2012;21(1):75-82.

90. Bruninga K, Camilleri M. Colonic motility and tone after spinal cord and cauda equina injury. Am J Gastroenterol. 1997;92(5):891-894.

91. Krassioukov A, et al. Neurogenic bowel management after spinal cord injury: a systematic review of the evidence. Spinal Cord. 2010;48(10):718-733.

92. Vallès $\mathrm{M}$, et al. Effect of sacral anterior root stimulator on bowel dysfunction in patients with spinal cord injury. Dis Colon Rectum. 2009;52(5):986-992.

93. Rasmussen MM, et al. Sacral anterior root stimulation improves bowel function in subjects with spinal cord injury. Spinal Cord. 2015;53(4):297-301.

94. Hinds JP, Wald A. Colonic and anorectal dysfunction associated with multiple sclerosis. $A m J$ Gastroenterol. 1989;84(6):587-595.

95. Lin SD, et al. The frequency of bowel and bladder problems in multiple sclerosis and its relation to fatigue: a single centre experience. PLoS One. 2019;14(9):e0222731.

96. Almeida MN, et al. Bowel symptoms predate the diagnosis among many patients with multiple sclerosis: a 14-year cohort study. Neurogastroenterol Motil. 2019;31(6):e13592.

97. Weber J, et al. Radiopaque markers transit and anorectal manometry in 16 patients with multiple sclerosis and urinary bladder dysfunction. Dis Colon Rectum. 1987;30(2):95-100.

98. Marola S, et al. Anal sphincter dysfunction in multiple sclerosis: an observation manometric study. Open Med (Wars). 2016;11(1):509-517.

99. Preziosi G, et al. Autonomic rectal dysfunction in patients with multiple sclerosis and bowel symptoms is secondary to spinal cord disease. Dis Colon Rectum. 2014;57(4):514-521.

100.Wiesel PH, et al. Gut focused behavioural treatment (biofeedback) for constipation and faecal incontinence in multiple sclerosis. J Neurol Neurosurg Psychiatry. 2000;69(2):240-243.

101.Popescu BF, et al. Neuromyelitis optica unique area postrema lesions: nausea, vomiting, and pathogenic implications. Neurology. 2011;76(14):1229-1237.

102. Bogdanos DP, et al. Association between Helicobacter pylori infection and Guillain-Barré syndrome: a meta-analysis. Eur J Clin Invest. 2020;50(5):e13218
103. Bertrand A, et al. Immune related adverse events associated with anti-CTLA-4 antibodies: systematic review and meta-analysis. BMC Med. 2015;13:211.

104. Counotte MJ, et al. Zika virus infection as a cause of congenital brain abnormalities and GuillainBarré syndrome: a living systematic review. F100ORes. 2018;7:196.

105. Ghannam M, et al. Neurological involvement of coronavirus disease 2019: a systematic review. J Neurol. 2020;267(11):3135-3153.

106. Ricci JA, et al. Upper gastrointestinal symptoms in a U.S. national sample of adults with diabetes. Scand J Gastroenterol. 2000;35(2):152-159.

107. Maleki D, et al. Gastrointestinal tract symptoms among persons with diabetes mellitus in the community. Arch Intern Med. 2000;160(18):2808-2816.

108. Chedid V, et al. Characterization of upper gastrointestinal symptoms, gastric motor functions, and associations in patients with diabetes at a referral center. Am J Gastroenterol. 2019;114(1):143-154

109. Vella A, et al. Effects of pramlintide, an amylin analogue, on gastric emptying in type 1 and 2 diabetes mellitus. Neurogastroenterol Motil. 2002;14(2):123-131.

110. Maselli DB, Camilleri M. Effects of GLP-1 and its analogs on gastric physiology in diabetes mellitus and obesity. Adv Exp Med Biol. 2020;1307:171-192.

111. Maleki D, et al. Pilot study of pathophysiology of constipation among community diabetics. Dig Dis Sci. 1998;43(11):2373-2378.

112. Valdovinos MA, et al. Chronic diarrhea in diabetes mellitus: mechanisms and an approach to diagnosis and treatment. Mayo Clin Proc. 1993;68(7):691-702.

113. Cowan AJ, et al. Amyloidosis of the gastrointestinal tract: a 13-year, single-center, referral experience. Haematologica. 2013;98(1):141-146.

114. Rubinow A, et al. Esophageal manometry in systemic amyloidosis. A study of 30 patients. Am J Med.1983;75(6):951-956.

115. Battle WM, et al. Gastrointestinal-motility dysfunction in amyloidosis. N Engl JMed. 1979;301(1):24-25.

116. Camilleri M, et al. Gastrointestinal motility disturbances in patients with orthostatic hypotension. Gastroenterology. 1985;88(6):1852-1859.

117. Wixner J, et al. Abnormal small bowel motility in patients with hereditary transthyretin amyloidosis. Neurogastroenterol Motil. 2018;30(9):e13354.

118. Afrough A, et al. Outcome of patients with immunoglobulin light-chain amyloidosis with lung, liver, gastrointestinal, neurologic, and soft tissue involvement after autologous hematopoietic stem cell transplantation. Biol Blood Marrow Transplant. 2015;21(8):1413-1417.

119. Wixner J, et al. Outcome of gastric emptying and gastrointestinal symptoms after liver transplantation for hereditary transthyretin amyloidosis. BMC Gastroenterol. 2015;15:51.

120. Gertz MA, et al. Advances in the treatment of hereditary transthyretin amyloidosis: a review. Brain Behav. 2019;9(9):e01371.

121. Tannoury J, et al. Contribution of immune-mediated paraneoplastic syndromes to neurological manifestations of neuroendocrine tumours: 
retrospective study. Neuroendocrinology. 2020;111(1-2):123-128.

122. Chinn JS, Schuffler MD. Paraneoplastic visceral neuropathy as a cause of severe gastrointestinal motor dysfunction. Gastroenterology. 1988;95(5):1279-1286.

123. Lennon VA, et al. Enteric neuronal autoantibodies in pseudoobstruction with small-cell lung carcinoma. Gastroenterology. 1991;100(1):137-142.

124.Vernino S, et al. Autoantibodies to ganglionic acetylcholine receptors in autoimmune autonomic neuropathies. $N$ Engl J Med. 2000;343(12):847-855.

125. Blackburn KM, et al. Neurological autoimmune disorders with prominent gastrointestinal manifestations: a review of presentation, evaluation, and treatment. Neurogastroenterol Motil. 2019;31(10):e13611

126.Sodhi N, et al. Autonomic function and motility in intestinal pseudoobstruction caused by paraneoplastic syndrome. $\mathrm{Dig} \mathrm{Dis}$ Sci. 1989;34(12):1937-1942.

127. Koike H, et al. Paraneoplastic neuropathy: wide-ranging clinicopathological manifestations. Curr Opin Neurol. 2011;24(5):504-510.

128. Berlin L, Cotton R. Gastro-intestinal manifestations of porphyria. Am J Dig Dis. 1950;17(4):110-114.

129. Stein JA, Tschudy DP. Acute intermittent porphyria. A clinical and biochemical study of 46 patients. Medicine (Baltimore). 1970;49(1):1-16.

130. Stölzel U, et al. Clinical guide and update on porphyrias. Gastroenterology. 2019;157(2):365-381.

131. Pedersen CE, et al. Constipation in children with neurofibromatosis type 1. J Pediatr Gastroenterol Nutr. 2013;56(2):229-232.

132. García Aroca J, et al. Intestinal pseudo-obstruction secondary to systemic neuropathies and myopathies. Cir Pediatr. 1994;7(3):115-120.

133. Bernardis V, et al. Intestinal leiomyosarcoma and gastroparesis associated with von Recklinghausen's disease. Digestion. 1999;60(1):82-85.

134.Dare AJ, et al. Abdominal neoplastic manifestations of neurofibromatosis type 1. Neurooncol
Adv. 2020;2(suppl 1):i124-i133.

135. Xie R, et al. Neurofibromatosis type 1-associated multiple rectal neuroendocrine tumors: a case report and review of the literature. World J Gastroenterol. 2018;24(33):3806-3812.

136. Marek T, et al. Expanding the phenotypic spectrum of lipomatosis of the sciatic nerve: earlyonset colonic diverticular disease. Neurogastroenterol Motil.2020;32(10):e13917.

137. Coker RJ, et al. Increased gut parasympathetic activity and chronic diarrhoea in a patient with the acquired immunodeficiency syndrome. Clin Auton Res. 1992;2(5):295-298.

138. Bardsley-Elliot A, Plosker GL. Nelfinavir: an update on its use in HIV infection. Drugs. 2000;59(3):581-620.

139. Beaugerie L, et al. Treatment of refractory diarrhoea in AIDS with acetorphan and octreotide: a randomized crossover study. Eur J Gastroenterol Hepatol.1996;8(5):485-489.

140. Nwachukwu CE, Okebe JU. Antimotility agents for chronic diarrhoea in people with HIV/AIDS. Cochrane Database Syst Rev. 2008;(4):CD005644

141. Dhamija R, et al. Serologic profiles aiding the diagnosis of autoimmune gastrointestinal dysmotility. Clin Gastroenterol Hepatol. 2008;6(9):988-992.

142.Pittock SJ, et al. Neural autoantibody evaluation in functional gastrointestinal disorders: a population-based case-control study. Dig Dis Sci. 2011;56(5):1452-1459.

143. Lennon VA, et al. Immunization with neuronal nicotinic acetylcholine receptor induces neurologic autoimmune disease. JClin Invest. 2003;111(6):907-913.

144.Borrelli O, et al. Evolution of gastric electrical features and gastric emptying in children with Duchenne and Becker muscular dystrophy. Am J Gastroenterol. 2005;100(3):695-702.

145. Laskin BL, et al. Novel gastrointestinal tract manifestations in juvenile dermatomyositis. J Pediatr. 1999;135(3):371-374.
146.Ebert EC. Review article: the gastrointestinal complications of myositis. Aliment Pharmacol Ther. 2010;31(3):359-365.

147. Lowsky R, et al. Familial visceral myopathy associated with a mitochondrial myopathy. Gut. 1993;34(2):279-283.

148. Filosto $\mathrm{M}$, et al. Pitfalls in diagnosing mitochondrial neurogastrointestinal encephalomyopathy. JInherit Metab Dis. 2011;34(6):1199-1203.

149. Pacitti D, et al. Mitochondrial neurogastrointestinal encephalomyopathy: Into the fourth decade, what we have learned so far. Front Genet. 2018;9:669.

150. Habibzadeh P, et al. Clinical and molecular characterization of a patient with mitochondrial neurogastrointestinal encephalomyopathy. $B M C$ Gastroenterol. 2020;20(1):142.

151. Filosto M, et al. Course and management of allogeneic stem cell transplantation in patients with mitochondrial neurogastrointestinal encephalomyopathy. J Neurol. 2012;259(12):2699-2706.

152. Yadak R, et al. Transplantation, gene therapy and intestinal pathology in MNGIE patients and mice. BMC Gastroenterol. 2018;18(1):149.

153. D'Angelo R, et al. Liver transplantation in mitochondrial neurogastrointestinal encephalomyopathy (MNGIE): clinical long-term follow-up and pathogenic implications. J Neurol. 2020;267(12):3702-3710.

154. Hilbert JE, et al. High frequency of gastrointestinal manifestations in myotonic dystrophy type 1 and type 2. Neurology. 2017;89(13):1348-1354.

155. Yoshida MM, et al. Megacolon in myotonic dystrophy caused by a degenerative neuropathy of the myenteric plexus. Gastroenterology. 1988;95(3):820-827.

156. Ho G, et al. Myotonic dystrophy type 1: clinical manifestations in children and adolescents. Arch Dis Child. 2019;104(1):48-52.

157. Pelizzo G, et al. Myotonic dystrophy type 1 and pseudo-obstruction in a child with smooth muscle $\alpha$-actin deficiency and eosinophilic myenteric plexitis. Turk J Gastroenterol. 2018;29(2):226-229. 